\title{
DIE TOEPASSING VAN DIE Q-METODE VAN DIE NIPN VIR POSWAARDERING BY KOÖPERASIES
}

\author{
A.L. BARNARD \\ DEPARTEMENT VAN BEDRYF- EN PERSONEELSIELKUNDE \\ POTCHEFSTROOMSE UNIVERSITEIT VIR C.H.O.
}

\begin{abstract}
SUMMARY
The application of the Q-method of job evaluation in 13 small, medium and big co-operatives, is discussed. Specific attention is given to the purpose and method of investigation; the findings and recommendations made to the various boards of directors as well as the specific problems encountered in the application of the Q-method and the establishment of an integrated salary structure. Differences between the three categories of cooperatives regarding pay curves, the under or over payment of comparable job grades etc., are discussed.
\end{abstract}

In opdrag van die direksies van koöperasies en in samewerking met die SuidAfrikaanse Instituut vir Koöperasies (SAIKO) is vanaf 1973 tot op hede 13 poswaarderingsprojekte afgehandel. ${ }^{*}$ Dit sluit 7 klein (minder as 150 Blankeposbekleërs), 3 middelslag (150-300 Blankeposbekleërs) en 3 groot (meer as 300 Blankeposbekleërs) koöperasies in, elkeen met sy unieke probleme en spesifieke behoeftes.

Die tydsduur van die projekte, wat in verskillende fases afgehandel is, het gewissel van 4 tot 15 maande. Die NIPN-metode (Naude, 1973) wat voorsiening maak vir 10 faktorskaaldefinisies, is gebruik om die verskillende poste in posgrade in te deel, terwyl vir die koppeling van posgraad en salaris weer grootliks van die metode van Paterson (1972, Volume 2), gebruik gemaak is.

\section{DOEL EN METODE VAN ONDERSOEK}

Die hoofdoel van die verskillende projekte was om 'n billike vergoedingskaal daar te stel wat verband hou met die relatiewe waarde van elke pos in die koöperasies. Vir hierdie

\footnotetext{
* Hierdie projekte word afgehandel in samewerking met dr. S.W. Krügel van die Departement Bedryfsielkunde aan die P.O. vir C.H.O.
} 
doel moes die kompleksiteitsvlak van elke pos, in verhouding met elke ander pos in die organisasie, bepaal word. Daarbenewens was die projek ook gerig op die daarstelling van 'n rasionele organisasiestruktuur, op die uitskakeling van personeelprobleme en op die blootlegging van inligting wat kon lei tot die optimale benutting, van die potensiaal van elke amptenaar in diens van die koöperasies. In hierdie artikel word egter slegs die bevindings en aanbevelings ten opsigte van die hoofdoelwit bespreek.

Die projekte is in drie hoof-fases afgehandel. Daar is eers na 'n volgende fase beweeg nadat die ondersoekspan hulself vergewis het van die feit dat die amptenare die betrokke fase behoorlik bemeester het. ' $n$ Betrokke fase het soms 'n volle ses maande geduur waartydens die ondersoekspan met gereelde tussenposes voorligting en verdere opleiding verskaf het. Die projekte is afgerond met ' $n$ verslag aan die verskillende direksies.

Die projek het uit die volgende drie fases bestaan:

1. 'n Paneel van poswaardeerders is opgelei. Om objektiwiteit te bevorder, is toegesien dat elke sektor in die koöperasie deur 'n poswaardeerder verteenwoordig is. Gedurende die opleiding is klem gele op die insameling, ontleding en beoordeling van spesifieke posinligting. Om hierdie taak te vergemaklik, is van 'n handleiding oor posontleding en posbeskrywing gebruik gemaak (Barnard, 1971).

2. Vervolgens is die werklike ontleding en beskrywing van alle sleutelposte uit al die sektore van die koöperasie se werksaamhede gedoen. Vir hierdie doel is die onderhoud, tesame met die NIPN-vraelys (Naude, 1973) gebruik.

Die stappe in die besluitnemingsproses, sowel as die afdeling "kontak met mense", is met meer voorbeelde as wat in die NIPN-handleiding voorsien is toegelig nadat dit in die eerste projekte as 'n leemte ervaar is. Aangesien hierdie fase besonder baie werk vereis, veral by die groot koöperasies met baie sleutelposte, is van 'n groot paneel ontleders gebruik gemaak.

3. Die slotgedeelte van die projek het bestaan uit ' $n$ intensiewe opleiding van die paneel in die hantering van die beoordelingsvorm van die NIPN (Naude, 1973), wat aan die hand van voorafbepaalde faktorskaaldefinisies ten opsigte van die twee faktore, $\mathrm{nl}$. besluitname en kontak met mense, opgestel is.

By die kleiner koöperasies is die aanvanklike paneel dikwels net so behou as beoordelaars, by die middelslag koöperasies is dit gewoonlik verklein - dog sorg is gedra dat elke afdeling verteenwoordig is. By die groot koöperasies is gewoonlik van 'n kernpaneel 
bestaande uit 'n aantal senior $( \pm 5)$ persone gebruik gemaak wat alle beoordelings gedoen het. Dit het eenvormigheid ten opsigte van standaard verseker. Hierdie paneel is telkens aangevul met persone uit die aanvanklike paneel uit wie se afdeling sekere poste op daardie tydstip beoordeel is.

$\mathrm{Na}$ die evaluering is die verskillende poste met betrekking tot hul numeriese totale in rangorde van laag tot hoog geplaas. Daar is sover as moontlik van natuurlike afsnypunte wat die skeidslyn tussen posgroepe op verskillende kompleksiteitsvlakke aandui sowel as van posprofiele gebruik gemaak om die poste in posgrade in te deel. Daar is ook krities na anomalieë, probleemgevalle sowel as grensposte gekyk in gevalle waar 'n natuurlike afsnypunt nie gevind is nie.

Die rekenkundige gemiddelde van salarisse (met die uitsluiting van salarisanomalieë) is volgens Paterson (1972, Volume 2) se aanwysings vir al die grade bereken en die salariskurwe is getrek om die huidige bestaande verband tussen posgraad en salaris aan te toon. 'n Salariskassie is volgens Paterson (1972, Volume 2) se metode getrek en anomalieë is met kringetjies aangedui. Dit was gevolglik met die eerste oogopslag duidelik watter posgrade se poste te hoog of te laag vergoed is. Om te bepaal of 'n betrokke koöperasie se salarisse in pas met die van ander koöperasies was, is poste uit verskillende posgrade met soortgelyke poste van vyf ander vergelykbare koöperasies, vergelyk.

Die projek is afgerond deur die koppeling van die onderskeie posgrade aan voorgestelde salarisskale. Soos in die geval van fase twee, is hierdie evaluering deur die paneel waardeerders gedoen, in samewerking met die ondersoekspan.

\section{BEVINDINGE EN AANBEVELINGS AAN DIE VERSKILLENDE DIREKSIES GEMAAK}

\section{Posgrade, salarisse, sleutelskale en kerwe}

\section{Bevinding 1:}

Dit was moontlik om die koöperasies se Blankeposte in agt grade in te deel (3-10). Die verskillende verbande wat tussen posgrade en salarisse vir die verskillende koöperasies aangetref is, word in die volgende tabel en figuur weergegee. 
TABEL 1

AANTAL KOÖPERASIES MET BEPAALDE VERBANDE TUSSEN POSGRAAD EN SALARIS

\begin{tabular}{|l|c|c|c|c|c|}
\hline $\begin{array}{l}\text { Soort } \\
\text { Koöperasies }\end{array}$ & $\begin{array}{c}\text { Aansienlike } \\
\text { kronkeling } \\
\text { in kurwe }\end{array}$ & $\begin{array}{c}\text { Geringe } \\
\text { kronkeling } \\
\text { in kurwe }\end{array}$ & $\begin{array}{c}\text { Kronkeling in } \\
\text { kurwe }\end{array}$ & $\begin{array}{c}\text { Aansienlike } \\
\text { terugsakking } \\
\text { in kurwe }\end{array}$ & $\begin{array}{c}\text { Duidelike } \\
\text { "hondebeen"- } \\
\text { kurwe }\end{array}$ \\
\hline Klein & & 3 & & 3 & 2 \\
\hline Middelslag & 1 & 2 & 3 & & \\
\hline Groot & & & 3 & & \\
\hline
\end{tabular}
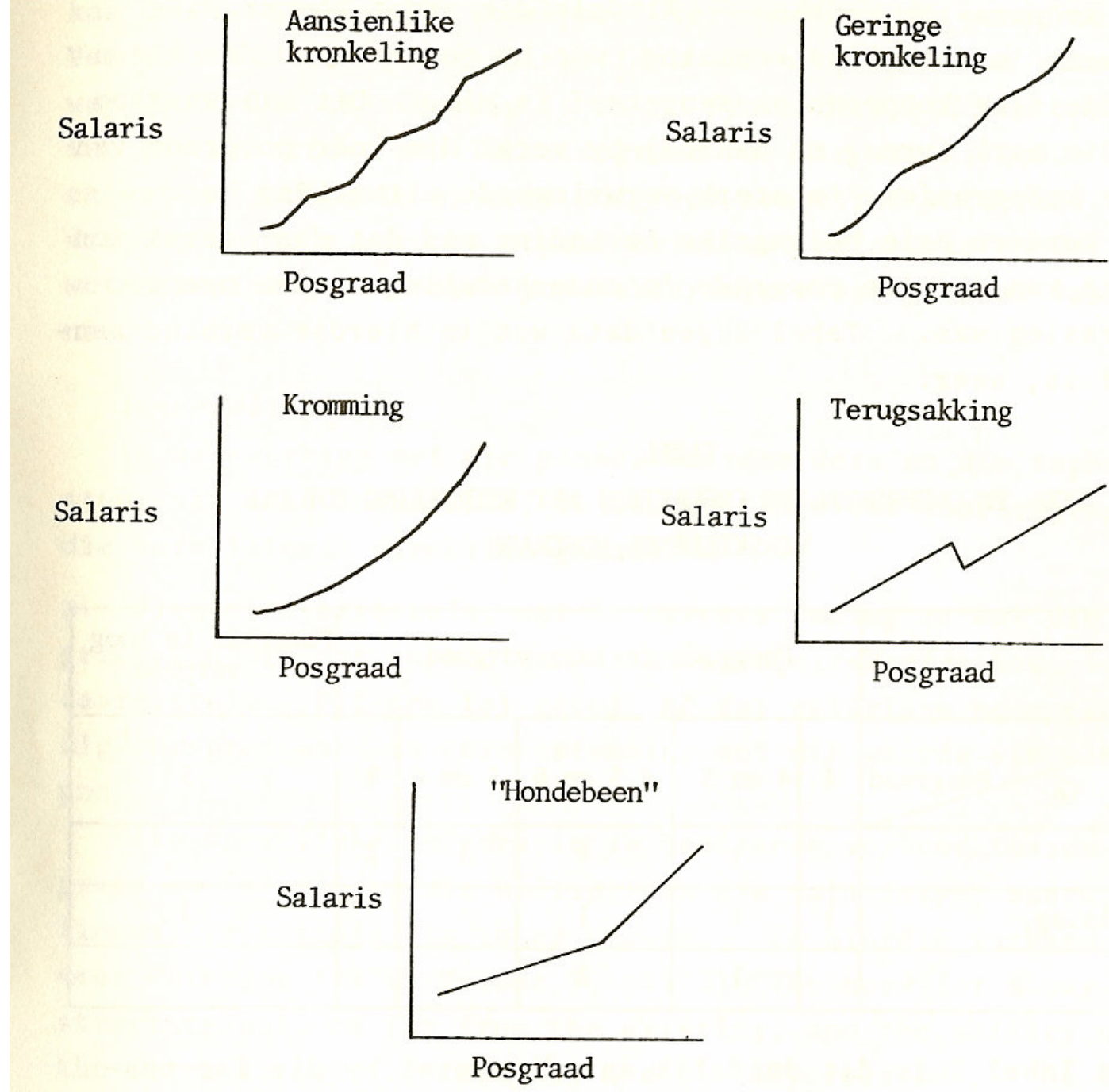

Figuur 1. Soort kurwes tussen posgraad en salaris 
Dit is opmerklik dat die kronkeling uitsluitlik by die klein en middelslag koöperasies aangetref is, terwyl die variasies hiervan, nl. die "terugsakking" en "hondebeen" slegs by klein koöperasies voorkom. Al drie die groot koöperasies toon weer 'n duidelike kromming, wat by geeneen van die klein en middelslag koöperasies aangetref is nie. Dit wil voorkom asof die mark (vraag en aanbod) by veral die hoër posgrade van groter koöperasies, 'n sterk verwringende uitwerking het.

'n Verdere baie belangrike bevinding was dat daar veral ten opsigte van die lae posgrade ' $n$ onderbetaling by die meeste koöperasies was. Tabel 2 gee data wat in hierdie verband aangetref is, weer:

$\underline{\text { TABEL } 2}$

\section{OOR- EN ONDERBETALING (RELATIEF) MET BETREKKING TOT DIE VERSKILLENDE POSGRADE}

\begin{tabular}{|l|c|c|c|c|c|c|}
\cline { 2 - 7 } \multicolumn{1}{c|}{} & \multicolumn{5}{c|}{ Posgrade te laag vergoed } & $\begin{array}{c}\text { Posgrade te hoog } \\
\text { vergoed }\end{array}$ \\
\hline $\begin{array}{l}\text { Soort Posgraad } \\
\text { Koöperasie }\end{array}$ & 4 & 4 en 5 & 4,5 en 6 & 5 en 6 & 8 & 5 \\
\hline Klein & & 1 & 4 & 1 & 2 & \\
\hline Middelslag & 1 & 1 & 1 & & & 1 \\
\hline Groot & & 1 & 2 & & & \\
\hline
\end{tabular}

Uit Tabel 2 is dit duidelik dat dit veral by die lae posgrade 4, 5 en 6 is waar bekleërs wat in 'n hoër posgraad lê, volgens 'n laer posgraad vergoed is. Hierdie neiging is feitlik by alle koöperasies, afgesien van grootte, waargeneem.

Die onderbetaling van veral dames, wat 'n aansienlike persentasie van die bekleërs by veral die laer posgrade uitmaak, kan deels vir hierdie verskynsel verantwoordelik gehou word. Verder moet die "gelykmakingseffek" (ten opsigte van salarisse) wat gewoonlik teenwoordig, is as 'n fyn onderskeid ten opsigte van die relatiewe moeilikheidsgraad van die verskillende poste en wat meer dikwels by laer posgrade aangetref word, nie uit die oog verloor word by organisasies wat salarisse sonder 'n wetenskaplik gefundeerde poswaarderingstelsel probeer vasstel nie. 


\section{Aanbeveling 1:}

In samewerking met die paneel waardeerders en die topbestuur van elke koöperasie, is aanbevelings vir voorlegging aan die verskillende direksies gemaak.

a. Sleutelsalarisskale, wat in ooreenstemming is met die graad van die pos en wat met markneigings rekening hou, is daargestel. Dit sou tot gevolg hê dat salarisse meer eweredig versprei word in ooreenstemming met die waarde van elke pos.

Elke spesifieke koöperasie se bestaande verband tussen posgraad en salarisse; die helling van die salarislyn, asook sy finansiële posisie, is in ag geneem. In hierdie verband beweer Paterson (1972, Volume 1, p.177) "The need for a pay structure not too far from the existing, and the ability of the firms to pay for changes, are closely related". Om die praktiese probleem van 'n té groot finansiële las te help verlig, was dit nodig om by meer as die helfte van die koöperasies van oorvleueling in skale gebruik te maak. Dit is natuurlik nie die ideale toestand van sake nie, maar indien alle bekleërs wat uit die onderste voorgestelde skale geval het, redelik gou ingebring moes word, sou dit 'n te groot finansiële las op koöperasies geplaas het. Deur die skale na ondertoe te verleng, was dit moontlik om 'n baie groter persentasie van die bekleërs in te sluit. Bekleërs wat ten spyte van die verlenging na onder nog steeds uitgeval het, moes oor 'n periode van 1-3 jaar, afhangende van elke koöperasie se finansiële posisie ingebring word. Goeie bekleërs moes hier vinniger ingebring word, as swak bekleërs.

Hierdie aanbeveling oor oorvleueling is beskou as 'n oorgangsmaatreël wat later geskrap, of wat ten minste verklein moes word. 'n Klein oorvleueling kan in elk geval in baie gevalle nuttig aangewend word om voorsiening te maak vir beginners en leerlinge.

By sommige van die koöperasies is skale op versoek van die topbestuur nie by die hoër posgrade 8, 9 en 10 voorsien nie. Dit het meer dikwels voorgekom by die middelslag en groot koöperasies asook ten opsigte van posgraad 10 by die klein koöperasies. Die relatief hoë salarisse wat deur die mark vir bogenoemde poste betaal is en wat dikwels ver uit verhouding was met dié van laer posgrade, het hier 'n deurslaggewende rol gespeel. Hierdie koöperasies het gewoonlik verkies dat daar 'n reglynige verband tussen salarisse en posgrade by die laer posgrade moes wees. Diesulkes het dan vaste salarisse vir hoër posgrade verkies aangesien daar anders van 'n nie-reglynige kurwe gebruik gemaak sou moes geword het. 
b. Afgesien van ' $n$ indeling van poste in posgrade (3-10) is by die direksies ook aanbeveel dat die salarisskale vir elke posgraad in twee en/of drie kategoriese (meer kategorieë by die laer posgrade) ingedeel word (A tot $\mathrm{C}$ ). Die voordele hieraan verbonde is dat:

- $\quad$ poste met 'n lae puntetelling in 'n posgraad byvoorbeeld in kategorie A geplaas is, waardeur bekleërs nie verder as die maksimum van kategorie A kon vorder nie;

- $\quad$ 'n gunstige markaanbod benut kon word, bv. getroude dames wat nie as broodwinners optree nie en slegs vir 'n kort periode 'n betrekking aanvaar;

- die grootte van die tak in oorweging geneem kon word. So bv. kan 'n klein tak kategorie A as maksimum hê, terwyl die groter tak (indien dit in dieselfde posgraad val) B as maksimum kan gebruik;

- $\quad$ dit voorsiening maak vir beginners en leerlinge en

- $\quad$ dit as 'n bevoegdheidsplafon kan dien.

c. Daar is voorts aanbeveel dat die salariskerwe wat in elke salarisskaal (van laag tot hoog) ingebou is, progressief behoort te wees om voldoende voorsiening vir inkomstebelasting en motivering van die bekleër te maak. Poste wat as gevolg van vraag en aanbod deur die mark hoog aangeslaan is, kon deur middel van 'n skaarsheidstoelaag apart voor voorsiening gemaak word, afgesien van die basiese (sleutel-) skaal. Dieselfde geld vir poste waaraan daar 'n mate van ontbering en ongunstige werksure verbonde was. Daar is aanbeveel dat beide bogenoemde faktore nie by die basiese (sleutel-) skaal ingesluit behoort te word nie aangesien omstandighede hierdie twee faktore binne 'n tydsperiode kon verander.

By die vasstelling van watter kerf in 'n skaal 'n persoon aangestel moet word, is aanbeveel dat die volgende faktore in aanmerking geneem word: Bekwaamheid, ondervinding, diensjare, skaarsheid, opleiding, ens. Die aanvaarding van hierdie skale het ook nie beteken dat ' $n$ jaarlikse verhoging vanselfsprekend toegeken moes word nie. Op grond van prestasiebeoordeling kon besluit word dat die posbekleër geen, een of meer kerwe moes ontvang.

d. Vir toekomstige skaalaanpassings is aanbeveel dat die staatsdiens, plaaslike besture en vergelykbare koöperasies as leidrade gebruik word. Vir kompetisiedoeleindes is periodieke aanpassings egter noodsaaklik.

e. By dié koöperasies wat van 'n lewenskostetoelaag gebruik gemaak het, is 'n aanpassing van $70 \%$ van die styging in verbruikersindeks aanbeveel om dit in pas met die aanbeveling van die anti-inflasiekomitee, te bring. Verder is aanbeveel dat by die herstrukturering van 
salarisskale die lewenskostestyging in die voorafgaande jare by die nuwe basiese skale gekonsolideer behoort te word. Dit is voorts aanbeveel dat lewenskostetoelaes geskei moes word van die basiese salaris.

f. Dit is ook by direksies sterk aanbeveel dat alle Nie-Blankeposte so gou doenlik in medewerking met SAIKO, oorweeg moes word. Die "Vaste-Graad-Metode" wat deur die NIPN ontwikkel is met die oog op laevlakposte, (Lätti en Breger 1976) is aanbeveel, aangesien dit by die Q-metode geïntegreer kon word om 'n eenvormige stelsel te gee (van Rooyen, 1978). In hierdie verband beweer Taylor (1978, p.4) "Experimental work done with the Fixed Grade Method and the Q-method indicates that the two systems link together with Grade 5 on both systems being more or less equivalent". Hierdie graad 5 waarna verwys word, is die wat aangetref word in die nuwe gids oor Universele graaddefinisies wat die oorspronklike 10 na 16 uitbrei.

\section{Bevinding 2}

Heelwat anomalieë, waar poste met 'n hoë puntetelling (en graad) te laag vergoed word, is by koöperasies aangetref. Soos reeds vermeld, (kyk tabel 2), het hierdie afwykings veral by posgrade 4, 5 en 6 voorgekom. Andersyds was daar ook enkele poste wat te hoog vergoed is met betrekking tot hulle puntetellings en posgrade.

\section{Aanbeveling 2}

By direksies is aanbeveel dat oplossings langs die weg van opgradering deur posverryking, opleiding, oorplasings asook salarisaanpassings gesoek moes word.

\section{Belangrike probleme tydens ondersoek ondervind}

\section{Met die toepassing van die NIPN-metode}

a. Vir elke verteenwoordigende pos is daarom drie besluite wat 'n posbekleër in die loop van sy werk geneem het, gevra. Verkieslik moes 'n voorbeeld van die volgende drie soorte besluite gegee word nl. 'n tegniese; interpersoonlike en skeppende besluit (Naude 1973). Dikwels het 'n besluit uit 'n mengsel van bogenoemde drie soorte bestaan terwyl daar by laer posgrade nie altyd sprake was van 'n skeppende en interpersoonlike besluit nie.

Dit is ook nodig gevind om meer voorbeelde by hierdie besluitnemingsgedeelte in te sluit met die oog op groter duidelikheid: Die vraag of ' $n$ besluit werklik eenmalig is ('n besluit wat volgens die NIPN-metode uitgesluit moet word) het ook soms hoofbrekens besorg. 
b. Landboukoöperasies het takke wat verskillende groottes aanneem en waaraan verskillende salarisskale gekoppel is. Omset speel by koöperasies 'n sleutelrol in die bepaling van die kategorie waarin 'n tak val. Die NIPN-metode het nie 'n groot onderskeid tussen hierdie takke aangedui nie met die gevolg dat takke wat volgens die koöperasies se kriteria in verskillende kategorieë tuishoort, dikwels deur die NIPN-metode in een posgraad geplaas is. Om hierdie probleem tot bevrediging van die koöperasies op te klaar en om ander redes (kyk Aanbeveling 1) is besluit om posgrade in kategorieë in te deel wat 'n onderskeid tussen die verskillende takke dus tog moontlik gemaak het.

c. Die oorspronklike Q-metode maak voorsiening vir 10 posgrade. Die eerste twee is egter vir baie on- en halfgeskoolde poste bedoel sodat Blankeposte feitlik sonder uitsondering by posgraad 3 begin het. Die feit dat dit vir slegs 8 salariskategorieë voorsiening gemaak het, is veral deur die groter koöperasies, wat self van 10 tot 15 kategorieë gebruik het, as 'n gebrek aangevoel. Hierdie probleem word egter nou opgelos deurdat die NIPN hulle nuwe universele graaddefinisies gepubliseer het, wat vir 16 grade voorsiening maak.

d. Die Q-metode maak van natuurlike afsnypunte gebruik om die poste (volgens hulle numeriese puntetelling) in posgrade in te deel. By veral die groter koöperasies met baie verteenwoordigende poste, is daar nie altyd sodanige natuurlike afsnypunte gevind nie. Met behulp van die evalueringsvorm, wat die minimum, gemiddelde en maksimum van 'n posgraad aandui, sowel as die posprofiel, moes soms op "willekeurige" afsnypunte teruggeval word. Hierdie afsnypunte moes dikwels weer verander word sodat poste met soortgelyke eienskappe saamgegroepeer kon word.

e. Die toepassing van die Q-metode het heelwat meer tyd in beslag geneem as waarvoor daar by menige koöperasie voor beplan was. Dieselfde bevinding word ook deur Richardt (1978) en Parkhurst (1978) gerapporteer op 'n poswaarderingsimposium wat deur die NIPN aangebied is.

f. 'n Laaste probleem wat ervaar is, is die van terminologie asook voorbeelde op die evalueringsvorm (geelkaart), wat dikwels meer verwarring veroorsaak het, as wat dit gehelp het. Soortgelyke probleme is ook deur Raubenheimer (1978) en Parkhurst (1978) op die poswaarderingsimposium van die NIPN gerapporteer.

\section{Probleme ondervind voortvloeiende uit die koppeling van posgrade met salarisskale}

a. 'n Salarisstruktuur is gewoonlik organisasiegebonde. 'n Struktuur wat vir een organisasie funksioneel en aanvaarbaar is, is volgens Human (1978) nie noodwendig so vir 'n 
ander nie. Dit het die ondersoekspan ook ten opsigte van koöperasies ondervind. Daar moes gevolglik vir elke koöperasie, met inagneming van sy spesifieke behoeftes, 'n eie struktuur ontwerp word. Verder het die NIPN eers onlangs begin om riglyne neer te lê ten opsigte van die aanpassing van die Q-metode by 'n bestaande salarisstruktuur (Human 1978).

b. Een van die grootste probleme wat ondervind is, is die feit dat daar feitlik 'n onderbetaling by alle koöperasies se laer posgrade aangetref is. Indien die ondersoekspan die beginsel van geen oorvleueling konsekwent toegepas het, sou die finansiële las te groot vir koöperasies gewees het om te dra. Daar is gevolglik by die meeste koöperasies van 'n oorvleueling in skale gebruik gemaak. Die omvang van die oorvleueling het gewissel afhangende van elke koöperasie se spesifieke omstandighede.

c. Die vraag watter verband tussen posgraad en salaris - die reglynige of nie-reglynige die ideale een is, het veral by die groter koöperasies meermale opgeduik. Dit was veral by die groter koöperasies waar die mark 'n verwringende uitwerking op veral die salarisse van die hoër posgrade gehad het. Die kleiner en sommige middelslag koöperasies het gewoonlik 'n reglynige verband verkies, terwyl die groter koöperasies 'n nie-reglynige een verkies het, met vaste salarisskale vir die hoëre posgrade (8-10).

\section{OPSOMMING}

Die toepassing van die Q-metode van poswaardering by 13 koöperasies, bestaande uit klein, middelslag en groot koöperasies, word bespreek. Aandag word veral aan die doel en metode van ondersoek gewy. Verder word bevindinge en aanbevelings aan die verskillende direksies bespreek rakende spesifieke probleme wat ervaar is met betrekking tot die toepassing van die $Q$-metode en die koppeling van posgrade met salarisskale. Verskille tussen die drie kategorië koöperasies ten opsigte van salariskurwes, oor- of onderbetaling van vergelykbare posgrade, ens. word aangedui.

\section{VERWYSINGS}

Barnard, A.L. Posontleding en Posbeskrywing. Potchefstroom, Wesvalia Boekhandel, 1971. Human, M.H. Aanpassing van 'n Bestaande Salarisstruktuur. Voordrag gelewer voor 'n poswaarderingsimposium van die NIPN, 8 Augustus 1978, Pretoria.

Naude, L. Poswaarderingshandleiding vir die NIPN-vraelysmetode. Johannesburg, 1973. Parkhurst, W.R. Organizational Factors and Aims Which Determine the Choice of a Job Evaluation Method. Voordrag gelewer voor ' $n$ poswaarderingsimposium van die NIPN, 8 Augustus 1978, Pretoria. 
Paterson, T.T. Job Evaluation. Volumes 1 en 2. London: Business Books. 1972.

Raubenheimer, I.v.W. Implementering van 'n Poswaarderingstelsel by die Administratiewe Vleuel van 'n Universiteit. Voordrag gelewer voor 'n poswaarderingsimposium van die NIPN, 8 Augustus 1978. Pretoria.

Richardt, A.J. Die Toepassing van die Q-metode van Poswaardering in 'n Semi-staatsorganisasie. Voordrag gelewer voor 'n poswaarderingsimposium van die NIPN, 8 Augustus 1978, Pretoria.

Taylor, J.M. A Job Evaluation Approach for Lower Level Workers: The Fixed Grade Method. Voordrag gelewer voor 'n poswaarderingsimposium van die NIPN, 8 Augustus 1978, Pretoria.

Lätti, V.I. en Breger, R.A. Job Grading Procedure for Selection and Placement of Workers at the Lower Levels. NIPN-verslag, Maart 1976.

Van Rooyen, J. Job Evaluation Approach. Voordrag gelewer voor 'n poswaarderingsimposium van die NIPN, 8 Augustus 1978, Pretoria. 
